\title{
Family Factors of Internet Addiction and Substance Use Experience in Taiwanese Adolescents
}

\author{
JU-YU YEN, M.D., ${ }^{1,2}$ CHENG-FANG YEN, M.D. Ph.D., ${ }^{1,3}$ \\ CHENG-CHUNG CHEN, M.D. Ph.D., ${ }^{3,4}$ SUE-HUEI CHEN, Ph.D., 5 \\ and CHIH-HUNG KO, M.D. ${ }^{1,6}$
}

\begin{abstract}
The aim of the study is to examine the differences in the diversity of family factors between adolescents with and without Internet addiction and substance use experience. A total of 3662 students (2328 boys and 1334 girls) were recruited from seven junior high schools, six senior high schools, and four vocational high schools in southern Taiwan. Internet addiction and substance experience were classified according to the score of Chen Internet Addiction Scale Questionnaires for Experience of Substance use. The family factors assessed included perceived family satisfaction, family economic status, parents' marriage status, care-givers, the frequency of intra-family conflict, families' habitual alcohol use, and perceived parents' or care givers' attitude toward adolescents' substance use. This study demonstrated that the characteristics of higher parent-adolescent conflict, habitual alcohol use of siblings, perceived parents' positive attitude to adolescent substance use, and lower family function could be used develop a predictive model for Internet addiction in the multiple logistic regression analysis. The former three family factors were also sufficient in themselves to develop a predictive model for substance use experience. The results revealed that adolescent Internet addiction and substance use experience shared similar family factors, which indicate that Internet addiction and substance use should be considered in the group of behavioral problem syndromes. A family-based preventive approach for Internet addiction and substance use should be introduced for adolescents with negative family factors.
\end{abstract}

\section{INTRODUCTION}

U SE OF THE INTERNET continues to rapidly spread. It has become a popular academic and entertainment tool of adolescents around the world. Adolescents are encouraged to utilize the Internet to enhance school performance and competitiveness; however, heavy use has several negative conse- quences. Internet addiction is one of the most serious problems. ${ }^{1-3}$ Adolescents who are addicted to the Internet also usually suffer from problems in their daily routine, school performance, family relationships, and mood. ${ }^{4-6}$ It is important, therefore, for mental health professionals to develop interventional strategies for preventing Internet addiction among adolescents. Hence, it is necessary to ex-

\footnotetext{
${ }^{1}$ Department of Psychiatry, Kaohsiung Medical University Chung-Ho Memorial Hospital, Kaohsiung, Taiwan.

${ }^{2}$ Department of Psychiatry, Kaohsiung Municipal Hsiao-Kang Hospital, Kaohsiung Medical University, Kaohsiung, Taiwan.

${ }^{3}$ Department of Psychiatry, College of Medicine, Kaohsiung Medical University, Kaohsiung, Taiwan.

${ }^{4}$ Jsyr-Huey Mental Hospital, Kaousiung Jen-I's Home, Kaohsiung, Taiwan.

${ }^{5}$ Department of Psychology, National Taiwan University, Taipei, Taiwan.

${ }^{6}$ Graduate Institute of Medicine, College of Medicine, Kaohsiung Medical University, Kaohsiung, Taiwan.
} 
amine both protective and risk factors for Internet addiction in adolescents, in order to develop such preventative strategies.

Since the family plays a central role in adolescents' socialization, ${ }^{7}$ family factors are reported to be one of the major risk factors of adolescent substance use. ${ }^{8}$ Adolescent substance use was found to be associated with broken parenting, ${ }^{9,10}$ parent-adolescent and intra-family conflicts, ${ }^{11,12}$ accepting attitudes of parents toward substance use of adolescents, ${ }^{13,14}$ and parental alcohol or tobacco use in the home. ${ }^{8,15}$ Poor family function has also been reported to correlate with Internet addiction in adolescents. ${ }^{16}$

However, to date, no report has focused on the association between adolescent Internet addiction and a diversity of family characteristics. Familybased preventive intervention has great promise in prevention of adolescent substance use. ${ }^{17}$ If adolescent Internet addiction and substance use share the same family factors, the family-based approach could become implemented as a solution for Internet addiction.

Thus, the aim of this study was to determine the association of Internet addiction and substance use experience with family-correlated factors including family economic status, parental marriage status, caregivers, the frequency of intra-family conflict, family habitual alcohol use, and perceived parental or caregiver attitudes toward adolescent substance use in Taiwanese adolescents.

\section{METHODS}

A total of 3662 students ( 2328 boys and 1334 girls) were recruited from seven junior high schools, six senior high schools, and four vocational high schools in southern Taiwan. Two classes were randomly selected from each grade of these schools. All students in selected classes were invited to complete the questionnaire anonymously after informed consent was obtained. The Chen Internet Addiction Scale (CIAS) ${ }^{18}$ was used to determine participant Internet addiction. The CIAS contains 26 items on a four-point Likert scale that assesses the severity of Internet-related problems. The internal reliability of the scale and the sub-scales in the original study range from 0.79 to $0.93 .{ }^{18}$ Based on diagnostic interviews assessing for criteria of Internet addiction, ${ }^{2}$ the $63 / 64$ cut-off point of CIAS had been determined to classify Internet addiction in adolescents with good diagnostic accuracy $(87.6 \%){ }^{19}$ Participants who scored higher than 63 on the CIAS were classified as Internet addicts. The Questionnaire for
Experience of Substance Use (Q-ESU) was used to assess whether participants habitually used tobacco, alcohol, and/or betel nut, and whether they had ever used cannabis, amphetamines, glue, heroin, ecstasy, or ketamine. ${ }^{20}$ The participants with positive responses to the above questions were classified as the substance use group.

Participants completed the Family APGAR Index (APGAR) to measure the level of satisfaction with various family functions. This index was originally developed by Smilkstein ${ }^{21}$ and was translated into Chinese by Chau et al. ${ }^{22}$ The five-point response scales range from "never" to "always." High scores indicate a good family function. Participants also completed questionnaires that assess demographic and family characteristics, including gender, age, family economic status, parents' marriage status, caregivers, the frequency of parental-adolescent and inter-parental conflict, family habitual alcohol use, and perceived parents' or caregivers' attitudes toward adolescent substance use.

\section{Statistical analysis}

Those who did not complete all measures-CIAS, Q-ESU, and APGAR-were excluded. Under control of gender, age, and school, we analyzed the association between Internet addiction and every family factor with logistic regression. The age, gender, and school factors were entered into the logistic regression models first. Then, the indicated family factor was entered, and the significance of prediction was determined. The significant family predictors were selected to conduct the multiple stepwise logistic regression analyses. The association between family factors and adolescent substance use was analyzed in the same way. A p-value less than 0.05 was considered significant.

\section{RESULTS}

A total of 3480 (95.0\%) participants (2189 boys and 1291 girls) completed all questionnaires, and these data were entered into the final statistical analyses. Demographic data are shown in Table 1. The mean age of the participants was $15.47 \pm 1.65$ years old. Among them, $20.7 \%$ were classified as the Internet addiction group, and $9.1 \%$ were classified as the substance use group.

The results of analyses for the association between Internet addiction and family factors by logistic regression under control of age, gender, and school are shown in Table 2. The results indicated that the adolescents with Internet addiction were 
Table 1. Demographic Data, Internet Addiction, and Substance Use Experience of Participants $(\mathrm{n}=3480)$

\begin{tabular}{lrrr}
\hline & $\mathrm{n}$ & $(\%)$ & Mean \pm SD \\
\hline Age, years & & & $15.47 \pm 1.65$ \\
Gender & & & \\
$\quad$ Male & 2189 & 62.9 & \\
$\quad$ Female & 1291 & 37.1 & \\
Level of education & 1443 & 41.5 & \\
$\quad$ Junior high school & 1120 & 32.2 & \\
$\quad$ Senior high school & 917 & 26.4 & \\
$\quad$ Vocational high school & & & \\
Grade & 489 & 14.1 & \\
$\quad$ Grade 7 & 511 & 14.7 & \\
$\quad$ Grade 8 & 443 & 12.7 & \\
$\quad$ Grade 9 & 681 & 19.6 & \\
$\quad$ Grade 10 & 547 & 15.7 & \\
$\quad$ Grade 11 & 23.2 & \\
$\quad$ Grade 12 & 809 & & \\
Internet addiction & & & \\
$\quad$ Yes & 721 & 20.7 & \\
$\quad$ No & 2759 & 79.3 & \\
Substance use experience & & & \\
$\quad$ Yes & 316 & 9.1 & \\
$\quad$ No & 3164 & 90.9 & \\
\hline
\end{tabular}

more likely to not be raised by parents, to have high parent-adolescent and inter-parental conflict, to have parents and siblings with habitual alcohol use, to have lower APGAR scores, and to perceive positive parental attitudes toward adolescent smoking, alcohol, and substance use.

The family factors that were significantly associated with Internet addiction were further fitted into the multiple logistic regression analysis, and the results are shown in Table 3. High parent-adolescent conflict was the most significant predictor since it was the first predictor entering the regression model. Other significant predictors included low APGAR score, sibling habitual alcohol use, and perceived positive parental attitudes toward adolescent substance use.

The result of regression analysis for substance use experience shown in Table 2 demonstrates that lower economic status, separated or divorced parents, not cared for by parents, high parent-adolescent conflict, high inter-parental conflict, habitual alcohol use of father, mother, and siblings, and perceived positive parental attitudes toward adolescent smoking, alcohol, and substance use predicted a high chance of substance experience significantly. Additionally, the APGAR score predicted a lower chance of substance use.
The family factors that were significantly associated with substance use experience were further fitted into the multiple logistic regression analysis (Table 3). Habitual alcohol use of siblings was the most significant predictor, since it was the first predictor entering the regression model. The other significant predictors included perceived positive parental attitudes toward adolescent substance use and high parent-adolescent conflict.

\section{DISCUSSION}

This study revealed that higher parent-adolescent conflict, habitual alcohol use of siblings, perceived positive parental attitudes toward adolescent substance use, and lower family functioning could be used to develop a predictive model for Internet addiction in the multiple logistic regression analysis. The former three family factors were also sufficient in themselves to develop a predictive model for substance use experience. The results demonstrated that adolescent Internet addiction and substance use experience share similar family factors.

We found that habitual alcohol use of siblings significantly predicted Internet addiction and sub- 
Table 2. Logistic Regression Analysis for the Family Predictors for Internet Addiction and Substance Experience in Adolescents under Control of Gender, Age, and SchoOl

\begin{tabular}{|c|c|c|c|c|c|c|}
\hline & \multicolumn{3}{|c|}{ Internet addiction } & \multicolumn{3}{|c|}{ Substance use } \\
\hline & Wald $\chi^{2}$ & $O R$ & $95 \% C I$ & Wald $\chi^{2}$ & OR & $95 \% C I$ \\
\hline APGAR score & $53.41^{* * *}$ & 0.92 & $0.90-0.94$ & $20.43^{* * *}$ & 0.93 & $0.90-0.96$ \\
\hline Lower economic status & 0.49 & 1.07 & $0.89-1.28$ & $5.94^{*}$ & 1.36 & $1.06-1.73$ \\
\hline Separated or divorced parents & 1.75 & 1.16 & $0.93-1.45$ & $10.66^{* *}$ & 1.61 & $1.21-2.14$ \\
\hline Not cared for by parents & $6.29^{*}$ & 1.35 & $1.07-1.70$ & $4.47^{*}$ & 1.41 & $1.03-1.93$ \\
\hline High parent-adolescent conflict & $69.36^{* * *}$ & 2.75 & $2.17-3.49$ & $39.83^{* * *}$ & 2.66 & $1.96-3.60$ \\
\hline High inter-parental conflict & $31.72^{* * *}$ & 1.99 & $1.57-2.53$ & $24.68^{* * *}$ & 2.20 & $1.61-3.00$ \\
\hline Habitual alcohol use of father & $9.70^{* *}$ & 1.32 & $1.11-1.57$ & $15.26^{* * *}$ & 1.62 & $1.27-2.06$ \\
\hline Habitual alcohol use of mother & $6.99 * *$ & 1.56 & $1.12-2.18$ & $45.71^{* * *}$ & 3.58 & $2.47-5.18$ \\
\hline Habitual alcohol use of siblings & $27.68^{* * *}$ & 1.83 & $1.46-2.30$ & $140.16^{* * *}$ & 5.04 & $3.86-6.59$ \\
\hline $\begin{array}{l}\text { Perceived positive parental attitude } \\
\text { to adolescent smoking }\end{array}$ & $6.84^{* *}$ & 1.67 & $1.14-2.44$ & $34.12^{* * *}$ & 3.46 & $2.28-5.25$ \\
\hline $\begin{array}{l}\text { Perceived positive parental attitude } \\
\text { to adolescent alcohol use }\end{array}$ & $5.08^{*}$ & 1.36 & $1.04-1.77$ & $36.65^{* * *}$ & 2.61 & $1.91-3.56$ \\
\hline $\begin{array}{l}\text { Perceived positive parental attitude } \\
\text { to adolescent substance use }\end{array}$ & $13.16^{* * *}$ & 2.35 & $1.48-3.72$ & $55.55^{* * *}$ & 6.25 & $3.86-10.1$ \\
\hline
\end{tabular}

stance use experience of adolescents. Corresponding to the results of a previous study, ${ }^{23}$ sibling alcohol use has a greater association with adolescent substance use than parent alcohol use in this study. Additionally, a similar association was found between sibling alcohol use and Internet addiction in this study. Although social learning theory was utilized to explain the association between sibling and adolescent alcohol use, ${ }^{24}$ it could not explain the association between sibling alcohol use and adolescent Internet addiction. Sibling alcohol use may be a result of poor family function; however, the habitual alcohol use of a sibling significantly predicted adolescent Internet addiction even after controlling for family function in the multiple regression model. Aside from family environmental factors, factors of other dimensions-including genetic factors accounting for an addiction-prone personality and comorbid psychiatric disorders-ought to be considered as underlying mechanisms deserving of further research.

High parent-adolescent conflict predicted Internet addiction and substance use in adolescents in this study. Ary et al. ${ }^{25}$ have reported that families with higher conflict have lower levels of parentchild involvement, which would result in inade-

Table 3. Multiple Logistic Regression Analysis for the Family Predictor of Internet Addiction and Substance Experience under Control of Gender, Age, and School

\begin{tabular}{|c|c|c|c|c|c|c|}
\hline & \multicolumn{3}{|c|}{ Internet addiction } & \multicolumn{3}{|c|}{ Substance use } \\
\hline & Wald $\chi^{2}$ & $A O R$ & $95 \% \mathrm{CI}$ & Wald $\chi^{2}$ & $A O R$ & $95 \% \mathrm{CI}$ \\
\hline High parent-adolescent conflict & $29.92^{* * *}$ & 2.21 & $1.67-2.94$ & $16.71^{* * *}$ & 2.17 & $1.50-3.14$ \\
\hline APGAR & $22.85^{* * *}$ & 0.94 & $0.91-0.96$ & - & - & - \\
\hline Habitual alcohol use of siblings & $12.82^{* * *}$ & 1.58 & $1.23-2.03$ & $104.11^{* * *}$ & 4.65 & $3.46-6.24$ \\
\hline $\begin{array}{l}\text { Perceived positive parental attitude } \\
\text { to adolescent substance use }\end{array}$ & $5.68^{*}$ & 1.93 & $1.12-3.31$ & $17.86^{* * *}$ & 3.79 & $2.04-7.04$ \\
\hline
\end{tabular}


quate parental monitoring, which would predict, in turn, adolescents being predisposed to Internet addiction. Furthermore, the social control theory suggests that, when adolescents are close to their parents, they feel obligated to act in non-deviant ways to please their parents. ${ }^{26,27}$ Thus, adolescents with higher conflict with parents would refuse to conform to the supervision of parents, including rules set for Internet use. Also, lacking support from parents, those adolescents seek social support from the interacting experiences on the Internet. ${ }^{28}$ Unfortunately, heavy Internet use by adolescents usually results in further conflict with their parents, which may make the problem of adolescent Internet addiction more difficult to resolve.

Inadequate parental supervision and discipline are usually a strong predictor of adolescent substance use. ${ }^{25,29}$ The present study demonstrates that perceived positive parental attitudes toward substance use predicts adolescent substance use and Internet addiction. Perceived positive parental attitudes toward substance use have been reported to be associated with adolescent substance use. ${ }^{30,31}$ Positive parental attitudes toward substance use represents ineffective family supervision, guidance, and discipline. According to social control theory, all adolescents have the impulse to act on their desires, but pro-social controls provided by families and other social institutions enable them to exert restraint. ${ }^{32}$ Internet activities usually provide the pleasure of control, interactive activity, and perceived fluidity of identity for adolescents. ${ }^{33}$ Without effective supervision and discipline in the family, adolescents usually have difficulty controlling time spent in ongoing online activities, such as online role-playing games.

Problem drinking, marijuana use, delinquent behaviors, and precocious sexual intercourse have been grouped as a syndrome of problem behaviors in adolescents. ${ }^{34,35}$ The social context model of the development of antisocial behavior has been reported to explain this problem behavior syndrome. $^{36}$ The model suggests that ineffective parental discipline and supervision, and poor intrafamily relationships are the first steps in the development of problematic behaviors. ${ }^{36}$ According to the results of the present study, adolescent Internet addiction and substance use were proved to share similar family factors, including habitual alcohol use of siblings, perceived positive parental attitudes toward substance use, and conflict with parents. Thus, the results of this study would suggest that adolescent Internet addiction may be one form of problem behaviors. However, further research to compare other social contexts of Internet addiction with those of other problem behaviors is necessary to validate this hypothesis.

The family-based approach has been reported to improve family function and decrease behavioral problems of children. ${ }^{17}$ Since adolescent Internet addiction shares the same family factors with substance use, the concept of family-based intervention for substance abuse might be utilized for Internet addiction. Based on the results of this study and previous reports of the family-based approach, ${ }^{17}$ we suggest that family-based prevention should include skills training for parents to improve communication skills in helping adolescents to develop social skills, helping family members reduce maladaptive family function, fostering skills for healthy family interactions, and effective family monitoring and discipline focusing on Internet addiction and substance use.

Our results should be interpreted in the light of several limitations. Firstly, societal restrictions on substance use may make adolescents unwilling to admit substance use even in anonymous questionnaires. Secondly, the cross-sectional research design of the present study could not confirm causal relationships of Internet addiction and substance use with family factors. Thirdly, lacking information from parents, assessment of family factors was based only on adolescents' reports.

\section{CONCLUSION}

This study examined the association between adolescent Internet addiction and a variety of family factors based on empirical research. It demonstrated that parent-adolescent conflict, lower family function, habitual alcohol use of sibling, and perceived positive parental attitudes toward adolescent substance use predicted adolescent Internet addiction. We found that Internet addiction and substance use in adolescents shared similar associated family factors, which indicate that Internet addiction and substance use might be included in the group of behavioral problems syndrome. A familybased preventive approach for Internet addiction and substance use should be implemented for adolescents with negative family factors.

\section{ACKNOWLEDGMENTS}

This study was supported by a grant of Kaohsiung Medical University Chung-Ho Memorial Hospital (kmhk-93-004). 


\section{REFERENCES}

1. Young, K.S. (1998). Internet addiction: the emergence of a new clinical disorder. CyberPsychology E Behavior 1:237-244.

2. Ko, C.H., Yen, J.Y., Chen, C.C., et al. (2005b). Proposed diagnostic criteria of Internet addiction for adolescents. Journal of Nervous and Mental Disease 193:728733.

3. Shapira, N.A., Lessig, M.C., Goldsmith, T.D., et al. (2003). Problematic internet use: proposed classification and diagnostic criteria. Depression $\mathcal{E}$ Anxiety 17:207-216.

4. Ryu, E.J., Choi, K.S., Seo, J.S., et al. (2004). [The relationships of Internet addiction, depression, and suicidal ideation in adolescents] [in Chinese]. Taehan Kanho. Hakhoe. Chi. 34:102-110.

5. Lin, S.S.J., \& Tsai, C.C. (2002). Sensation seeking and internet dependence of Taiwanese high school adolescents. Computers in Human Behavior 18:411-426.

6. Young, K.S., \& Rogers, R.C. (1998). The relationship between depression and Internet addiction. CyberPsychology \& Behavior 1:25-28.

7. Barker, J.C., \& Hunt, G. (2006). Representations of family: a review of the alcohol and drug literature. International Journal of Drug Policy 15:347-356.

8. Jacob, T., \& Johnson, S.L. (1999). Family influences on alcohol and other substance use. In: Ott, P.J., Tarter, R.E., Ammerman, R.T., \& Tarter, R.E. (eds.), Source book on substance abuse Boston: Allyn and Bacon, pp. 165-174.

9. Niaz, U., Siddigui, S.S., Hassan, S., et al. (2005). A survey of psychosocial correlates of drug abuse in young adults aged 16-21, in Karachi: identify "high risk" population to target intervention strategies. Pakistan Journal of Medical Science 21:271-277.

10. Emery, R.E., Waldron, M., Kitzmann, K.M., et al. (1999). Delinquent behavior, future divorce or nonmarital childbearing, and externalizing behavior among offspring: a 14-year prospective study. Journal of Family Psychology 61:568-579.

11. Parker, J.S., \& Benson, M.J. (2004). Parent-adolescent relations and adolescent functioning: self-esteem, substance abuse, and delinquency. Adolescence 39: 519-530.

12. Hops, H., Tildesley, E., Lichtenstein, E., et al. (1990). Parent-adolescent problem-solving interactions and drug use. American Journal of Drug and Alcohol Abuse 16:239-258.

13. Beal, A.C., Ausiello, J., \& Perrin, J.M. (2001). Social influences on health-risk behaviors among minority middle school students. Journal of Adolescent Health 28:474-480.

14. Bogenschneider, K., Wu, M.Y., Raffaelli, M., et al. (1998). Parent influences on adolescent peer orientation and substance use: the interface of parenting practices and values. Child Development 69:1672-1688.

15. Webster, R.A., Hunter, M., \& Keats, J.A. (1994). Peer and parental influences on adolescents' substance use: a path analysis. International Journal of Addictions 29:647-657.

16. Ko, C.H., Yen, J.Y., Chen, C.C., et al. (2005a). Gender differences and related factors affecting online gaming addiction among Taiwanese adolescents. Journal of Nervous and Mental Disease 193:273-277.

17. Lochman, J.E., \& Van den Steenhoven, A. (2006). Family-based approaches to substance abuse prevention. Journal of Primary Prevention 23:49-114.

18. Chen, S.H., Weng, L.C., Su, Y.J., et al. (2003). Development of Chinese Internet Addiction Scale and its psychometric study. Chinese Journal of Psychology 45: 279-294.

19. Ko, C.H., Yen, J.Y., Yen, C.F., et al. (2005b). Screening for Internet addiction: an empirical research on cut-off points for the Chen Internet Addiction Scale. Kaohsiung Journal of Medical Sciences 21:545551.

20. Yen, C.F., Yang, Y.H., Ko, C.H., et al. (2005). Substance initiation sequences among Taiwanese adolescents using methamphetamine. Psychiatry and Clinical Neurosciences 59:683-689.

21. Smilkstein, G. (1978). The family APGAR: a proposal for a family function test and its use by physicians. Journal of Family Practice 6:1231-1239.

22. Chau, T.T., Hsiao, T.M., Huang, C.T., et al. (1991). A preliminary study of family Apgar index in the Chinese. Kaohsiung Journal of Medical Sciences 7: 27-31.

23. Fagan, A.A., \& Naiman J.M. (2005). The relative contributions of parental and sibling substance use to adolescent tobacco, alcohol, and other drug use. Journal of Drug Issues 35:869-884.

24. Bahr, S.J., Hoffmann, J.P., \& Yang, X. (2005). Parental and peer influences on the risk of adolescent drug use. Journal of Primary Prevention 26:529-551.

25. Ary, D.V., Duncan, T.E., Biglan, A., et al. (1999). Development of adolescent problem behavior. Journal of Abnormal Child Psychology 27:141-150.

26. Rankin, J.H., \& Kern, R. (1994). Parental attachments and delinquency. Criminology 32:495-515.

27. Wright, J.P., \& Cullen, F.T. (2001). Parental efficacy and delinquent behavior: do control and support matter? Criminology 39:677-704.

28. Tichon, J.G., \& Shapiro, M. (2003). The process of sharing social support in cyberspace. CyberPsychology $\mathcal{E}$ Behavior 6:161-170.

29. Eitle D. (2005). The moderating effects of peer substance use on the family structure-adolescent substance use association: quantity versus quality of parenting. Addictive Behaviors 30:963-980.

30. Ary, D.V., Tildesley, E., Hops, H., et al. (1993). The influence of parent, sibling, and peer modeling and attitudes on adolescent use of alcohol. International Journal of Addictions 28:853-880.

31. Nelson, B.V., Patience, T.H., \& MacDonald, D.C. (1999). Adolescent risk behavior and the influence of parents and education. Journal of the American Board of Family Practice 12:436-443. 
32. Hirschi, T. (1969). Causes of delinquency. Berkeley: University of California Press.

33. Leung, L. (2004). Net-generation attributes and seductive properties of the internet as predictors of online activities and internet addiction. CyberPsychology $\mathcal{E}$ Behavior 7:333-348.

34. Donovan, J.E., Jessor, R., \& Costa, F.M. (1988). Syndrome of problem behavior in adolescence: a replication. Journal of Consulting and Clinical Psychology 56: 762-765.

35. Donovan, J.E., \& Jessor, R. (1985). Structure of problem behavior in adolescence and young adulthood. Journal of Consulting and Clinical Psychology 53:890-904.
36. Metzler, C.W., Noell, J., Biglan, A., et al. (1994). The social context for risky sexual behavior among adolescents. Journal of Behavioral Medicine 17:419-438.

Address reprint requests to: Dr. Chih-Hung Ko Department of Psychiatry Kaohsiung Medical University $100 \mathrm{Tzyou}^{\text {st }} \mathrm{Rd}$. Kaohsiung City, Taiwan 807

E-mail: cyberko@seed.net.tw 